\title{
Liquid-liquid equilibrium for the quaternary system propionic acid $+n$-propanol $+n$-propyl propionate + water at 293.15, 313.15 and 333.15 K
}

\author{
Artemiy Samarov, Maria Toikka, Maya Trofimova, Alexander Toikka*
}

Department of Chemical Thermodynamics and Kinetics, Saint Petersburg State University, Universitetskiy prospect 26, Peterhof, St. Petersburg 198504, Russia

\begin{abstract}
Liquid-liquid equilibrium (LLE) for the quaternary system propionic acid $+n$-propanol $+n$-propyl propionate + water and for the ternary sub-systems propionic acid $+n$-propyl propionate + water and n-propanol $+\mathrm{n}$-propyl propionate + water were studied at 293.15, 313.15 and $333.15 \mathrm{~K}$ and atmospheric pressure. Binodal surface in quaternary system and binodal curves in ternary systems were determined. Experimental LLE data were compared with the values calculated by NRTL models, these data are in good agreement.
\end{abstract}

Keywords: Liquid-liquid equilibria, $n$-propyl propionate, NRTL model

\section{Introduction}

The data on phase diagrams of heterogeneous systems are of well-known importance for the design of modern industrial processes. $n$-Propyl propionate is one of commonly used solvents having a lot of practical applications. This ester is used in many different fields, for example, as a constituent part of coatings, printing inks, air freshener, confecting essence, detergent and other industrial products. $n$-Propyl propionate is readily biodegradable and it is expected to be rapidly degraded in wastewater treatment plants or in the environment [1]. $n$-Propyl propionate is generally synthesized by the esterification reaction of propionic acid with $n$-propanol. The complex process of its production involves reaction and separation operations. One of the best and well-known chemical engineering processes which combines chemical reaction and separation into a multifunctional reactor is a reactive distillation [2] and [3]. The limited mutual solubility of components of $n$-propyl propionate synthesis reaction should be taken into account in reactive distillation design. For example, one can use the advantage of the phase splitting by coupling the distillation column with a liquid-liquid separator [4]. For this reason the majority of recent papers on $n$-propyl propionate production include the discussion of the splitting in propionic acid $+n$-propanol $+n$-propyl propionate + water system [1,4-10]. Nevertheless the available experimental data sets on LLE were presented for binary sub-systems and for ternary $n$-propanol + water $+n$-propyl propionate system only [11]. The LLE in this ternary system was studied by Altman et al at $288.15 \mathrm{~K}$ [5] and by Mozzhukhin et al at $293.15 \mathrm{~K}$ [12]. The aim of our work was to study LLE for quaternary system propionic acid $+n$-propanol $+n$-propyl propionate + water and for both ternary sub-system propionic acid $+n$-propyl propionate + water and $n$-propanol $+n$-propyl propionate + water with miscibility gap at three temperatures, 293.15, 313.15 and $333.15 \mathrm{~K}$. The sets of obtained experimental data gave us the opportunity to present in more details the binodal surface and tielines position of the system with $n$-propyl propionate synthesis reaction in composition triangle and composition tetrahedron. It should be noted that there is a lack of the data on LLE in propionic acid $+n$-propanol $+n$-propyl propionate + water system in modern literature. The set of the data on LLE in quaternary system should give the additional opportunities for the optimization of the processes of $n$-propyl propionate synthesis and for the design of coupled processes, e.g. reactive distillation.

\section{Experimental}

\footnotetext{
${ }^{*}$ Corresponding author: a.toikka@spbu.ru
} 


\subsection{Materials}

Propionic acid (> 0.99 mole fraction, Vekton, Russia), $n$-propanol (>0.99 mole fraction, Vekton, Russia) and $n$-propyl propionate ( $>0.98$ mole fraction, Sigma Aldrich) were purified by distillation, water was bidistilled. Purity was determined by gas chromatography (GC) and is given in Table 1. All physical-chemical constants of pure substances are in agreement with the literature data [13].

\section{Table 1}

The purities of the chemicals.

\begin{tabular}{ll}
\hline Substance & Purity, mole fraction ${ }^{\mathrm{a}}$ \\
\hline Propionic acid & 0.998 \\
$n$-Propanol & 0.995 \\
$n$-Propyl propionate & 0.980 \\
Water & 0.999 \\
\hline aThe uncertainty is estimated to be \pm 0.002 mole fraction. $^{2}$
\end{tabular}

\subsection{LLE determination}

The study of the phase equilibria was carried out by method described in [14] using GC analysis for analytical determination of phase compositions. Firstly, binary, ternary and quaternary mixtures of known overall composition within the heterogeneous region were prepared in glass vials $(5 \mathrm{ml})$ by gravimetric method using analytical balance Shinko VIBRA HT-120CE (Japan). Heterogeneous mixtures were stirred in sealed vials. Then vessels were placed in the liquid thermostat $(293.15,313.15$ and $333.15 \mathrm{~K})$. We consider that the equilibrium is reached when there is a full separation of the phases: phases become completely transparent and there is no variation of compositions with a time. After reaching of phase equilibrium, samples were taken from both phases with chromatographic syringe ("Hamilton", USA) and analyzed by GC. To avoid the splitting of samples directly into the needle the chromatographic syringe was preliminary heated. Gas chromatograph "Chromatec Crystal 5000.2" (Russia) with thermal conductivity detector (TCD) and packed column Porapak R ( $1 \mathrm{~m}^{*} 3 \mathrm{~mm}$ i.d.) was used. The TCD was chosen because of the presence of water. Helium with the flow rate of $60 \mathrm{ml} / \mathrm{min}$ was used as a carrier gas. Operating temperature of column, vaporizing injector and TCD were $483 \mathrm{~K}, 503.15 \mathrm{~K}$ and $513 \mathrm{~K}$, respectively. The methods of internal standard and relative calibration were used to calculate compositions of equilibrium liquid phases. Propionic acid was accepted as linking component. Uncertainty of GC analysis averaged \pm 0.005 mole fraction. Accuracy of initial solutions preparing is $0.001 \mathrm{~g}$. The temperature uncertainty of the liquid thermostat was $\pm 0.05 \mathrm{~K}$. The reproducibility of the experimental data was confirmed by the repeated analysis of samples. All equilibrium liquid phases were analyzed 3-5 times and the deviations of the results were in the frame of GC analysis uncertainties.

\section{Results and discussions}

\subsection{Experimental data}

The LLE data for the ternary sub-systems propionic acid $+n$-propyl propionate + water and $n$-propanol $+n$-propyl propionate + water at 293.15, 313.15 and $333.15 \mathrm{~K}$ and atmospheric pressure are presented in Tables 2 and 3, respectively (mole fractions).

The Fig. 1 shows binodal curves and tie-lines of LLE of the ternary sub-system propionic acid $+n$-propyl propionate + water at $293.15,313.15$ and $333.15 \mathrm{~K}$.

The solubility in the ternary system $n$-propanol $+n$-propyl propionate + water at 293.15 , 313.15 and $333.15 \mathrm{~K}$ is presented on Fig. 2. The data of Altman et al at $288.15 \mathrm{~K} \mathrm{[5]}$ are also presented for comparison. As usual the solubility increases with temperature and the area of immiscibility at $288.15 \mathrm{~K}$ covers a larger area in comparison with $308.15 \mathrm{~K}$ and $333.15 \mathrm{~K}$. In both systems the immiscibility area slightly depends on temperature (decrease with the temperature 
rising). The LLE tie-lines are presented for $333.15 \mathrm{~K}$ only. For other temperatures the general disposition of tie-lines is approximately the same.

The LLE data for the quaternary system propionic acid $+n$ - propanol $+n$-propyl propionate + water at 293.15, 313.15 and $333.15 \mathrm{~K}$ and atmospheric pressure are presented in Table 4 (mole fractions). The initial series of quaternary solutions were prepared with keeping of constant ratio of propionic acid and $n$-propanol that is $1: 1$. These compositions conveniently display the form of binodal surfaces in composition tetrahedron. The view of the surface for $293.15 \mathrm{~K}$ is presented on Fig. 3.

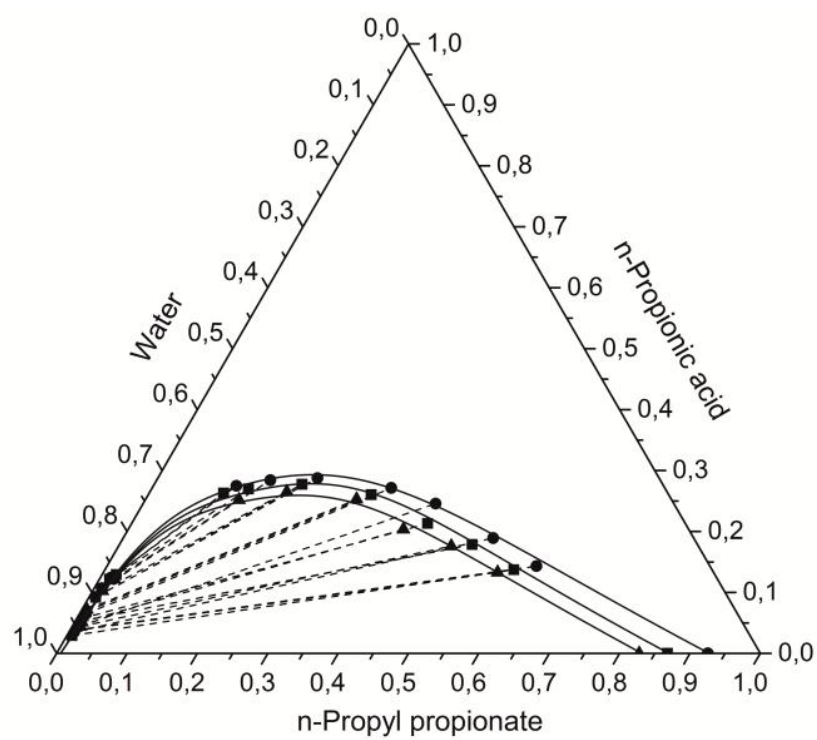

Fig. 1. The diagram of the LLE in ternary system propionic acid $+n$-propyl propionate + water: $\bullet---$

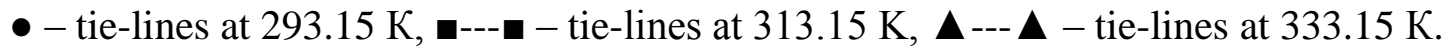

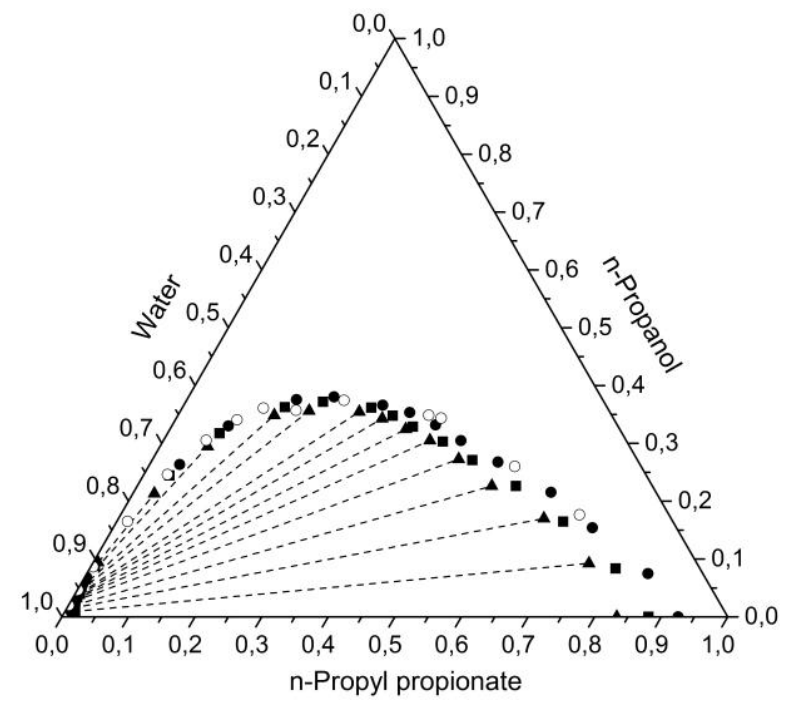

Fig. 2. The solubility in ternary system $n$-propanol $+n$-propyl propionate + water: $\odot-288.15 \mathrm{~K}$ [5], $\bullet-293.15 \mathrm{~K}, \boldsymbol{\square}-313.15 \mathrm{~K}, \boldsymbol{\Delta}-333.15 \mathrm{~K}, \boldsymbol{\Delta}--\mathbf{\Delta}-$ tie-lines at $333.15 \mathrm{~K}$. 


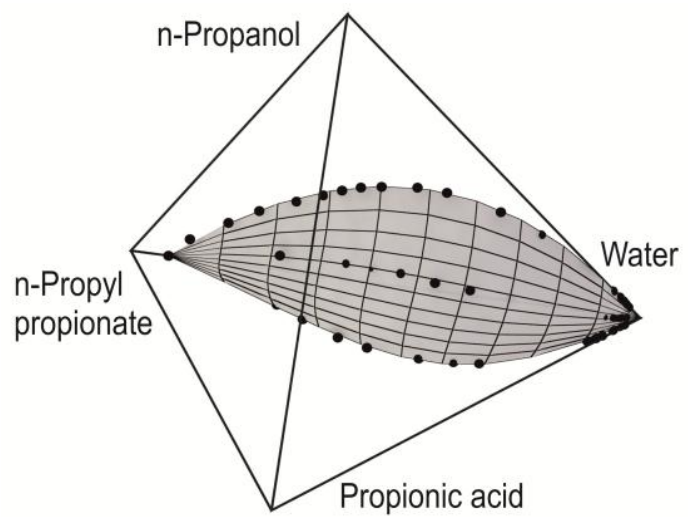

Fig 3. The qualitative view of the binodal surface of quaternary system propionic acid $+n$-propanol $+n$-propyl propionate - water at $333.15 \mathrm{~K}$.

\section{Table 2}

The experimental LLE data for the ternary system propionic acid (1) $+n$-propyl propionate $(2)+$ water (3) (mole fractions $x$, atmospheric pressure ${ }^{a}$ )

\begin{tabular}{|c|c|c|c|}
\hline \multicolumn{2}{|c|}{ Water phase } & \multicolumn{2}{|c|}{ Organic phase } \\
\hline$x_{1}$ & $x_{2}$ & $x_{1}$ & $x_{2}$ \\
\hline \multicolumn{4}{|c|}{$293.15 \mathrm{~K}$} \\
\hline 0.000 & 0.006 & 0.000 & 0.926 \\
\hline 0.038 & 0.004 & 0.143 & 0.610 \\
\hline 0.035 & 0.008 & 0.189 & 0.526 \\
\hline 0.044 & 0.010 & 0.246 & 0.416 \\
\hline 0.064 & 0.009 & 0.272 & 0.340 \\
\hline 0.093 & 0.009 & 0.288 & 0.227 \\
\hline 0.107 & 0.011 & 0.284 & 0.162 \\
\hline 0.124 & 0.015 & 0.275 & 0.118 \\
\hline \multicolumn{4}{|c|}{$\begin{array}{c}\sigma(\mathrm{NRTL})=4.1 \% \\
313.15 \mathrm{~K}\end{array}$} \\
\hline 0.000 & 0.009 & 0.000 & 0.881 \\
\hline 0.029 & 0.007 & 0.137 & 0.581 \\
\hline 0.053 & 0.007 & 0.178 & 0.501 \\
\hline 0.057 & 0.006 & 0.213 & 0.421 \\
\hline 0.069 & 0.008 & 0.260 & 0.317 \\
\hline 0.092 & 0.010 & 0.277 & 0.210 \\
\hline 0.122 & 0.015 & 0.270 & 0.138 \\
\hline 0.129 & 0.020 & 0.263 & 0.106 \\
\hline \multirow{2}{*}{\multicolumn{4}{|c|}{$\begin{array}{c}\sigma(\text { NRTL })=3.2 \% \\
333.15 \mathrm{~K}\end{array}$}} \\
\hline & & & \\
\hline 0.000 & 0.013 & 0.000 & 0.828 \\
\hline 0.037 & 0.004 & 0.133 & 0.560 \\
\hline 0.044 & 0.012 & 0.176 & 0.473 \\
\hline 0.051 & 0.011 & 0.204 & 0.391 \\
\hline 0.072 & 0.007 & 0.253 & 0.300 \\
\hline 0.103 & 0.014 & 0.265 & 0.195 \\
\hline 0.122 & 0.021 & 0.252 & 0.133 \\
\hline \multicolumn{4}{|c|}{$\sigma(\mathrm{NRTL})=3.1 \%$} \\
\hline
\end{tabular}


Table 3

The experimental LLE data for the ternary system $n$-propanol $(1)+n$-propyl propionate $(2)+$ water (3) (mole fractions $x$, atmospheric pressure ${ }^{a}$ )

\begin{tabular}{|c|c|c|c|}
\hline \multicolumn{2}{|c|}{ Water phase } & \multicolumn{2}{|c|}{ Organic phase } \\
\hline$x_{1}$ & $x_{2}$ & $x_{1}$ & $x_{2}$ \\
\hline \multicolumn{4}{|c|}{$293.15 \mathrm{~K}$} \\
\hline 0.000 & 0.006 & 0.000 & 0.926 \\
\hline 0.013 & 0.011 & 0.073 & 0.842 \\
\hline 0.022 & 0.008 & 0.154 & 0.720 \\
\hline 0.031 & 0.007 & 0.214 & 0.625 \\
\hline 0.035 & 0.005 & 0.268 & 0.521 \\
\hline 0.038 & 0.003 & 0.305 & 0.447 \\
\hline 0.041 & 0.003 & 0.332 & 0.395 \\
\hline 0.044 & 0.004 & 0.353 & 0.346 \\
\hline 0.046 & 0.004 & 0.366 & 0.299 \\
\hline 0.052 & 0.004 & 0.381 & 0.219 \\
\hline 0.053 & 0.003 & 0.378 & 0.195 \\
\hline 0.056 & 0.003 & 0.376 & 0.164 \\
\hline 0.068 & 0.003 & 0.330 & 0.085 \\
\hline \multicolumn{4}{|c|}{$\begin{array}{c}\sigma(\mathrm{NRTL})=2.9 \% \\
313.15 \mathrm{~K}\end{array}$} \\
\hline 0.000 & 0.009 & 0.000 & 0.881 \\
\hline 0.010 & 0.015 & 0.084 & 0.790 \\
\hline 0.017 & 0.006 & 0.165 & 0.671 \\
\hline 0.027 & 0.007 & 0.226 & 0.569 \\
\hline 0.029 & 0.004 & 0.271 & 0.481 \\
\hline 0.033 & 0.002 & 0.303 & 0.421 \\
\hline 0.036 & 0.005 & 0.329 & 0.363 \\
\hline 0.038 & 0.003 & 0.348 & 0.323 \\
\hline 0.041 & 0.004 & 0.362 & 0.284 \\
\hline 0.045 & 0.003 & 0.372 & 0.206 \\
\hline 0.051 & 0.004 & 0.363 & 0.154 \\
\hline 0.065 & 0.003 & 0.318 & 0.078 \\
\hline 0.088 & 0.006 & 0.244 & 0.040 \\
\hline \multirow{2}{*}{\multicolumn{4}{|c|}{$\begin{array}{c}\sigma(\mathrm{NRTL})=2.2 \% \\
333.15 \mathrm{~K}\end{array}$}} \\
\hline & & & \\
\hline 0.000 & 0.013 & 0.000 & 0.828 \\
\hline 0.009 & 0.012 & 0.092 & 0.745 \\
\hline 0.015 & 0.007 & 0.170 & 0.639 \\
\hline 0.020 & 0.008 & 0.226 & 0.533 \\
\hline 0.027 & 0.005 & 0.273 & 0.460 \\
\hline 0.030 & 0.004 & 0.305 & 0.400 \\
\hline 0.033 & 0.005 & 0.325 & 0.354 \\
\hline 0.037 & 0.007 & 0.343 & 0.310 \\
\hline 0.040 & 0.006 & 0.354 & 0.270 \\
\hline 0.044 & 0.004 & 0.356 & 0.193 \\
\hline 0.048 & 0.003 & 0.349 & 0.145 \\
\hline 0.065 & 0.004 & 0.295 & 0.072 \\
\hline 0.094 & 0.007 & 0.213 & 0.032 \\
\hline \multicolumn{4}{|c|}{$\sigma(\mathrm{NRTL})=3.2 \%$} \\
\hline
\end{tabular}

${ }^{\text {a }}$ Standard uncertainties $\mathrm{u}(\mathrm{x})=0.005, \mathrm{u}(\mathrm{T})=0.05$ 


\section{Table 4}

The experimental LLE data for the quaternary system propionic acid (1) $+n$-propanol $(2)+n$ propyl propionate (3) + water (4) (mole fractions $x$, atmospheric pressure ${ }^{a}$ )

\begin{tabular}{|c|c|c|c|c|c|}
\hline \multicolumn{3}{|c|}{ Water phase } & \multicolumn{3}{|c|}{ Organic phase } \\
\hline$x_{1}$ & $x_{2}$ & $x_{3}$ & $x_{1}$ & $x_{2}$ & $x_{3}$ \\
\hline \multicolumn{6}{|c|}{$293.15 \mathrm{~K}$} \\
\hline 0.022 & 0.016 & 0.006 & 0.098 & 0.145 & 0.481 \\
\hline 0.029 & 0.022 & 0.012 & 0.119 & 0.168 & 0.393 \\
\hline 0.032 & 0.022 & 0.006 & 0.132 & 0.173 & 0.330 \\
\hline 0.037 & 0.025 & 0.007 & 0.146 & 0.182 & 0.260 \\
\hline 0.045 & 0.030 & 0.007 & 0.164 & 0.180 & 0.181 \\
\hline 0.048 & 0.034 & 0.006 & 0.162 & 0.167 & 0.122 \\
\hline 0.060 & 0.042 & 0.007 & 0.143 & 0.140 & 0.071 \\
\hline \multicolumn{6}{|c|}{$313.15 \mathrm{~K}$} \\
\hline 0.023 & 0.017 & 0.016 & 0.091 & 0.146 & 0.459 \\
\hline 0.031 & 0.018 & 0.008 & 0.107 & 0.168 & 0.376 \\
\hline 0.033 & 0.020 & 0.007 & 0.125 & 0.171 & 0.312 \\
\hline 0.033 & 0.022 & 0.005 & 0.140 & 0.176 & 0.245 \\
\hline 0.042 & 0.027 & 0.006 & 0.155 & 0.172 & 0.171 \\
\hline 0.049 & 0.032 & 0.006 & 0.147 & 0.159 & 0.114 \\
\hline 0.061 & 0.045 & 0.009 & 0.131 & 0.125 & 0.061 \\
\hline \multicolumn{6}{|c|}{$333.15 \mathrm{~K}$} \\
\hline 0.025 & 0.009 & 0.008 & 0.047 & 0.106 & 0.589 \\
\hline 0.028 & 0.014 & 0.009 & 0.079 & 0.148 & 0.446 \\
\hline 0.033 & 0.018 & 0.012 & 0.103 & 0.166 & 0.363 \\
\hline 0.036 & 0.019 & 0.009 & 0.117 & 0.171 & 0.302 \\
\hline 0.038 & 0.022 & 0.008 & 0.135 & 0.170 & 0.232 \\
\hline 0.044 & 0.027 & 0.007 & 0.151 & 0.166 & 0.160 \\
\hline 0.052 & 0.034 & 0.007 & 0.147 & 0.151 & 0.107 \\
\hline
\end{tabular}

\subsection{Reliability of tie-line data}

To check the reliability of the experimental data on LLE we used the Bachman equation [15]:

$\ln \left(\frac{W_{1}^{A}}{W_{4}^{A}}\right)=a+b \ln \left(\frac{W_{1}^{O}}{W_{3}^{O}}\right)$

and Hand equation [16]:

$W_{3}^{o}=a+b\left(\frac{W_{3}^{o}}{W_{4}^{A}}\right)$

where $W_{1}^{A}$ is the mass fraction of propionic acid (or $n$-propanol) in the water-rich phase, $W_{4}^{A}$ is the mass fraction of water in the water-rich phase, $W_{1}^{0}$ is the mass fraction of propionic acid (or $n$ propanol) in the organic phase, $W_{3}^{O}$ is the mass fraction of $n$-propyl acetate in the organic phase, $a$ and $b$ are adjustable parameters. Correlations with the use of Bachman and Hand equation are shown in Fig. 4 and Fig. 5, respectively.

The correlation factor $\mathrm{R}^{2}$ values were determined by a partial least-squares regression. The correlation factor for Bachman and Hand test in the case of propionic acid $+n$-propyl propionate + water system indicates the consistency of the LLE data: $\mathrm{R}^{2}>0.95$. The same result of Bachman 
correlation $\left(\mathrm{R}^{2}>0.95\right)$ is for $n$-propanol $+n$-propyl propionate + water system. The Hand plot in the case of $n$-propanol $+n$-propyl propionate + water system has not linear form: there are inflection points on the graphs (Fig. 5). Such behavior could be explained by the tie-line disposition and peculiarity of changes of organic phase composition. First, the concentration of $n$-propanol in the organic phase increases, but then, closer to the critical point, begins to diminish. It also follows from the critical point disposition and, respectively, from the asymmetric shape of binodal curve. In this case, additionally to Bachman equation, we correlated LLE data with the use of polynomial dependence:

$W_{3}^{O}=a+b\left(\frac{W_{3}^{O}}{W_{4}^{A}}\right)+c\left(\frac{W_{3}^{O}}{W_{4}^{A}}\right)^{2}+d\left(\frac{W_{3}^{O}}{W_{4}^{A}}\right)^{3}$

The correlation factor calculated for equation (3), $\mathrm{R}^{2}>0.95$, along with Bachman correlation, indicates the consistency of the measured LLE data.

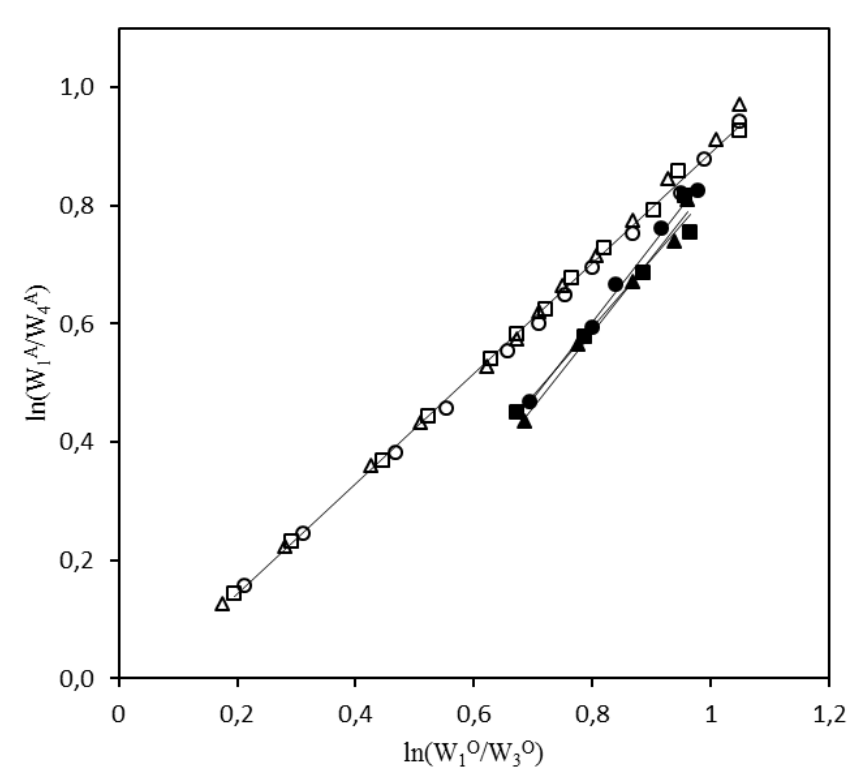

Fig. 4. Bachman plot for the ternary system $n$-propanol $+n$-propyl propionate + water: $\circ-293.15$ $\mathrm{K}, \square-313.15 \mathrm{~K}, \Delta-333.15 \mathrm{~K}$; and ternary system propionic acid + $n$-propyl propionate + water: $-293.15 \mathrm{~K}, \boldsymbol{-}-313.15 \mathrm{~K}, \boldsymbol{\Delta}-333.15 \mathrm{~K}$.

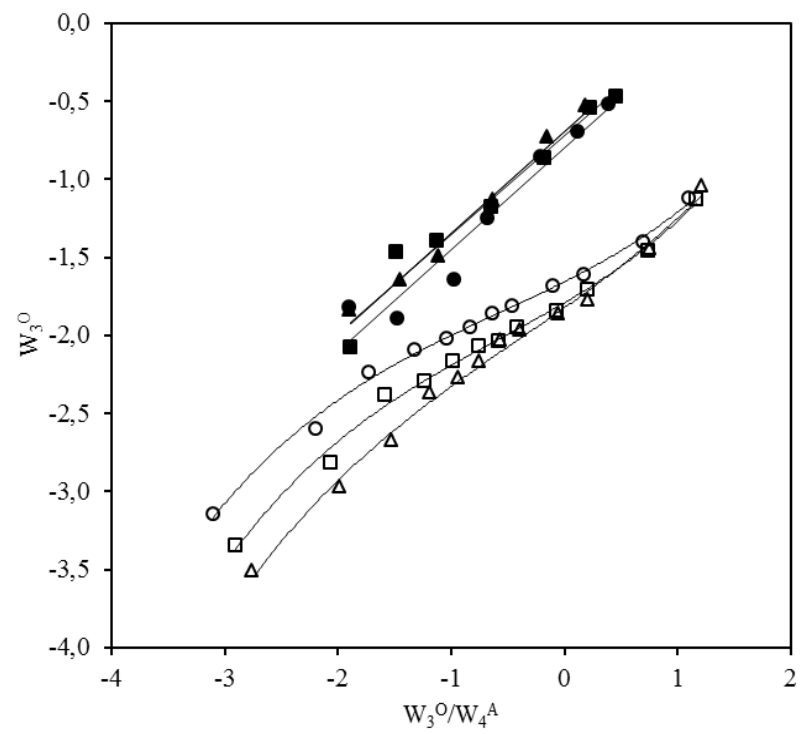

Fig. 5. Hand plot for the ternary system $n$-propanol $+n$-propyl propionate + water: $\circ-293.15 \mathrm{~K}$, $\square$ $-313.15 \mathrm{~K}, \Delta-333.15 \mathrm{~K}$; and ternary system propionic acid + $n$-propyl propionate + water: $\bullet-$ $293.15 \mathrm{~K}, \mathbf{\square}-313.15 \mathrm{~K}, \boldsymbol{\Delta}-333.15 \mathrm{~K}$. 


\section{Modeling of LLE}

The experimental data on ternary and quaternary systems were correlated by NRTL model [17]. The NRTL equation for the activity coefficients in the solution of $n$ components was used in the following form:

$$
\begin{aligned}
& \ln \left(\gamma_{i}\right)=\frac{\sum_{j=1}^{m} x_{j} \tau_{j i} G_{j i}}{\sum_{l=1}^{m} x_{l} G_{l i}}+\sum_{j=1}^{m} \frac{x_{j} G_{i j}}{\sum_{l=1}^{m} x_{l} G_{l j}}\left(\tau_{i j}-\frac{\sum_{r=1}^{m} x_{r} \tau_{r j} G_{r j}}{\sum_{l=1}^{m} x_{l} G_{l j}}\right) \\
& \tau_{j i}=\frac{g_{j i}-g_{i i}}{R T}=\frac{\Delta g_{j i}}{R T} \\
& G_{j i}=\exp \left(-\alpha_{j i} \tau_{j i}\right) \\
& \left(\alpha_{j i}=\alpha_{i j}\right)
\end{aligned}
$$

where $g_{j i}$ is energy parameter that characterizes the interaction of components $j$ and $i$; parameter $\alpha_{j i}$ is responsible for the nonrandomness in the systems. Optimization of NRTL parameters was carried out by minimization of objective function $(\mathrm{OF})$ :

$$
O F=\sum_{k=1}^{n} \sum_{i=1}^{n}\left[\left(x_{i k}^{e x p}-x_{i k}^{c a l}\right)_{o r}^{2}+\left(x_{i k}^{e x p}-x_{i k}^{c a l}\right)_{w}^{2}\right]
$$

The parameters estimated by this procedure are presented in Table 5. These parameters were obtained by correlation of the quaternary and the ternary systems.

\section{Table 5}

Binary parameters for NRTL simulation

\begin{tabular}{ccccccc}
\hline & $\begin{array}{l}\text { propionic } \\
\text { acid }-n- \\
\text { propanol }\end{array}$ & $\begin{array}{l}\text { propionic } \\
\text { acid - water }\end{array}$ & $\begin{array}{l}\text { pacid }-n \text { - } \\
\text { propyl } \\
\text { propionate }\end{array}$ & $\begin{array}{l}n \text { - propanol } \\
\text { - water }\end{array}$ & $\begin{array}{l}n \text {-propanol } \\
n \text { - propyl } \\
\text { propionate }\end{array}$ & $\begin{array}{l}n \text {-propyl } \\
\text { propionate }- \\
\text { water }\end{array}$ \\
\hline$\Delta g_{j i} / \mathrm{J} \mathrm{mol}^{-1}$ & 1120.8 & 1631.9 & 590.0 & 1744.7 & 566.0 & 3505.0 \\
$\Delta g_{i j} / \mathrm{J} \mathrm{mol}^{-1}$ & 1754.0 & -182.3 & 32.1 & -93.5 & 236.9 & 1142.5 \\
$\alpha_{j i}$ & 0.3 & 0.3 & 0.3 & 0.3 & 0.3 & 0.3 \\
\hline
\end{tabular}

Standard deviation, $\sigma$ was determined:

$$
\sigma(\%)=100 \sqrt{\frac{\sum_{k=1}^{n} \sum_{i=1}^{4}\left(x_{i k}^{e x p}-x_{i k}^{c a l}\right)_{o r}^{2}+\left(x_{i k}^{e x p}-x_{i k}^{c a l}\right)_{w}^{2}}{2 m n}}
$$

where $n$ is a number of tie-lines, $m$ is a number of components. Subscripts $i, k$ indicate components and tie-lines respectively; or, $w$ - organic and water phases.

The results of NRTL modeling both for quaternary and ternary systems are in good agreement with experimental data. Accordingly, these parameters are suitable for data correlation for the whole composition range of quaternary system. Standard deviation for subsystems propionic acid $+n$-propyl propionate + water and $n$-propanol $+n$-propyl propionate + water and quaternary system propionic acid $+n$-propanol $+n$-propyl propionate + water does not exceed $4.1 \%$.

\section{Conclusions}


LLE data for the quaternary system propionic acid $+n$-propanol $+n$-propyl propionate + water and for the ternary subsystems propionic acid $+n$-propyl propionate + water and $n$-propanol + $n$-propyl propionate + water were obtained at 293.15, 313.15 and $333.15 \mathrm{~K}$ and atmospheric pressure. These set of new experimental data allow presenting the binodal surface in composition tetrahedron. Verification the reliability of the experimental data on LLE was carried out using Bachman and Hand equations. The comparison of experimental LLE data with the values which were calculated using NRTL model indicates that the experimental and calculated data are in sufficient agreement. Obtained NRTL parameters may be used for the data correlation in the whole composition range of quaternary system.

\section{Acknowledgments}

Authors acknowledge Saint Petersburg State University for the research grant 12.38.257.2014. Artemiy Samarov is grateful to Russian Foundation for Basic Research for the support of this study (RFBR project 16-33-60128). Maria Toikka is grateful for the scholarship of President of Russian Federation (SP-2140.2016.1). Authors are also grateful to NIST ThermoData Engine group for the data on the properties of considered system.

\section{References}

[1] M. Cruz-Díaz, C. Buchaly, P. Kreis, E.S. Pérez-Cisneros, R. Lobo-Oehmichen, A. Górak, Synthesis of n-propyl propionate in a pilot-plant reactive distillation column: Experimental study and simulation, Comput. Chem. Eng. 39 (2012) 118-128.

doi:10.1016/j.compchemeng.2012.01.004.

[2] K. Sundmacher, Kienle A. ( Eds .), Reactive Distillation Status and Future Directions WileyVCH, Verlag GmbH \& Co. KGaA, Weinheim, 2003.

[3] A. Gorak, E. Sorensen, Distillation Fundamentals and Principles, 1st Edition. Ed. Academic Press., 2014.

[4] T. Keller, J. Muendges, A. Jantharasuk, C.A. Gónzalez-Rugerio, H. Moritz, P. Kreis, A. Górak, Experimental model validation for n-propyl propionate synthesis in a reactive distillation column coupled with a liquid-liquid phase separator, Chem. Eng. Sci. 66 (2011) 4889-4900. doi:10.1016/j.ces.2011.06.056.

[5] E. Altman, G.D. Stefanidis, T. Van Gerven, A.I. Stankiewicz, Phase Equilibria for Reactive Distillation of Propyl Propanoate. Pure Component Property Data, Vapor - Liquid Equilibria, and Liquid - Liquid Equilibria, J. Chem. Eng. Data. 56 (2011) 2322-2328. doi:dx.doi.org/10.1021/je101302p.

[6] H. Xu, Q. Ye, H. Zhang, J. Qin, N. Li, Design and control of reactive distillation-recovery distillation flowsheet with a decanter for synthesis of N-propyl propionate, Chem. Eng. Process. Process Intensif. 85 (2014) 38-47. doi:10.1016/j.cep.2014.08.001.

[7] X. Dai, Q. Ye, H. Yu, X. Suo, R. Li, Design and control of dividing-wall column for the synthesis of n-propyl propionate by reactive distillation, Ind. Eng. Chem. Res. 54 (2015) 3919-3932. doi:10.1021/acs.iecr.5b00147.

[8] C. Buchaly, P. Kreis, A. Gorak, N-propyl propionate synthesis via catalytic distillation Experimental investigation in pilot-scale, Ind. Eng. Chem. Res. 51 (2012) 891-899. doi:10.1021/ie102225t.

[9] E. Altman, P. Kreis, T. van Gerven, G.D. Stefanidis, A. Stankiewicz, A. G??rak, Pilot plant synthesis of n-propyl propionate via reactive distillation with decanter separator for reactant recovery. Experimental model validation and simulation studies, Chem. Eng. Process. Process Intensif. 49 (2010) 965-972. doi:10.1016/j.cep.2010.04.008.

[10] E. Altman, G.D. Stefanidis, T. Van Gerven, A.I. Stankiewicz, Process intensification of reactive distillation for the synthesis of $n$-propyl propionate: The effects of microwave radiation on molecular separation and esterification reaction, Ind. Eng. Chem. Res. 49 (2010) 10287-10296. doi:10.1021/ie100555h. 
[11] A.M. Toikka, A.A. Samarov, M.A. Toikka, Phase and chemical equilibria in multicomponent fluid systems with a chemical reaction, Russ. Chem. Rev. 84 (2015) 378-392. doi:10.1070/RCR4515.

[12] A.S. Mozzhukhin, L.A. Serafimov, V.A. Mitropolskaya, L.M. Sankina, Liquid - vapour and liquid-liquid phase equilibria in the Propan-1-ol - water - propyl propionate system at 760 mmHg, Russ J. Phys. Chem. (1967) 902-903.

[13] M. Frenkel, R.D. Chirico, V. Diky, A.F. Kazakov, C.D. Muzny, J.W. Magee, I. Abdulagatov, K. Kroenlein, J.W. Kang, NIST ThermoData Engine, NIST Standard Reference Database 103b-Pure Compounds, Binary Mixtures, and Chemical Reactions, Version 5.0; Standard Reference Data Program, National Institute of Standards and Technology, Gaithersburg, MD, 2010.

[14] M. Toikka, A.A. Samarov, M. Trofimova, A. Golikova, N. Tsvetov, A. Toikka, Solubility, liquid-liquid equilibrium and critical states for the quaternary system acetic acid-ethanolethyl acetate-water at 303.15 K and 313.15 K, Fluid Phase Equilib. 373 (2014) 72-79. doi:10.1016/j.fluid.2014.04.013.

[15] I. Bach, I. Bachman, Tie Lines in Ternary Liquid Systems, Ind. Eng. Chem. 12 (1940) 38-39.

[16] D.B. Hand, Dineric distribution, J. Phys. Chem. 34 (1930) 1961-2000.

[17] H. Renon, J.M. Prausnitz, Local compositions in thermodynamic excess functions for liquid mixtures, AIChE J. 14 (1968) 135-144. doi:10.1002/aic.690140124. 